\title{
Disparity of women's awareness of cardiovascular and cancer risks
}

\begin{abstract}
Objective: To assess women's awareness of cardiovascular disease and cancer risks.

Study design: We conducted a survey of women's general knowledge about cardiovascular disease, and breast, colon, cervical cancer risks and collected demographic features of the participants. The data were analyzed using multiple logistic regression and Pearson Chi-squared analysis.
\end{abstract}

Results: Two hundred fifty six surveys were collected and analyzed. There was a strong association between participants' ethnicity, education level, and annual income, and their awareness level of cardiovascular disease and cancer risks $(\mathrm{p}<0.05)$.

Conclusion: Women from minority ethnic groups with lower education and income levels would benefit from improved counseling on cardiovascular disease and cancer prevention.

Keywords: awareness, cancer risks, cardiovascular, women's health
Volume 5 Issue 5 - 2017

\author{
Michelle Quinn,' Larisa Gavrilova-Jordan, ${ }^{2}$ \\ Lawrence Devoe, ${ }^{2}$ Teresa Hubka, 'Elena \\ Trukhacheva' \\ 'Department of Obstetrics and Gynecology, Midwestern \\ University, USA \\ ${ }^{2}$ Department of Obstetrics and Gynecology, Georgia Regents \\ University, Georgia
}

Correspondence: Larisa Gavrilova-Jordan, Department of Obstetrics and Gynecology, Georgia regents University, I I 20 15th Street, BB-7516A, Augusta, 30912, Georgia, Tel 706-7224434, Fax 706-72I-62II, Email Igavrilovajordan@augusta.edu

Received: July 07, 2017 | Published: July 19, 2017

\section{Introduction}

Cardiovascular disease (CVD) and cancer are the two leading causes of women's mortality in the United States. ${ }^{1}$ To lower the CVD-related morbidity and mortality requires the modification of well-known CVD risk factors such as hypertension, smoking, obesity, hyperlipidemia and diabetes. ${ }^{2}$ Patient awareness of CVD risk factors and their prevention is lacking, exemplified by the fact that only onethird of Americans are aware of this common diagnosis. ${ }^{3}$ The Center for Disease Control and Preventions (CDC) has endorsed patient education about risk factors with their subsequent modification as an effective preventive strategy. ${ }^{4}$

Early detection of cancer through regular screening of women for breast, cervical and colorectal cancer has led to earlier treatment and lower cancer-related deaths in the United States. ${ }^{5}$ The significant declination of the advanced stages of breast and cervical cancers is the results of the effective prevention program with regular mammography, cervical cytology, HPV testing, and in recent years HPV vaccination. ${ }^{6,7}$ Screening strategies for breast and cervical cancer have been successfully embedded into women's care; however, colon cancer screening is suboptimal with only $63 \%$ of American women receiving appropriate testing. ${ }^{8-10}$ Awareness about CVD and cancer prevention may improve patient adherence to current screening guidelines and may further decrease CVD and cancer associated morbidity and mortality in women. The objective of this study was to assess women's awareness of CVD and breast, cervical and colon cancers and to identify predictors of knowledge deficiencies for these conditions.

\section{Material and methods}

A survey of women's knowledge regarding the risk factors and screening tests for cardiovascular disease, breast, colon, and cervical cancer was conducted. A standardized 15 question survey was developed (See Appendix A), based on information from the CDC, USPSTF, and ACOG recommendations. ${ }^{6,8,11-15}$ The primary outcome was the number of correct responses by participants. Secondary outcomes included demographic characteristics of all participating women and how they were related to specific knowledge deficiencies. The study was approved by the Institutional Review Board of Midwestern University.

From February 2012-July 2012, a standardized survey questionnaire was administered voluntarily, to women 18-60years of age at an obstetric/gynecologic resident clinic, a private obstetric and gynecologic office, and a private infertility practice. Demographic characteristics of the participants included age, race, highest school grade completed, employment, insurance type, annual family income, marital status, and parity. All collected anonymous surveys were scored by the number of correct answers. Total scores ranged from 0-15 and were categorized as low scoring (fewer than three correct responses in the specific knowledge category) and high scoring (three or more correct responses in the specific knowledge category). After their surveys were collected, all participants received a copy of the correct answers. The study data was analyzed using multiple logistic regression and Pearson Chi-squared analysis using SPSS 18 software. $P$ value $<0.05$ was considered statistically significant.

\section{Results}

Two hundred fifty six surveys were analyzed. Table 1 depicts study participant demographic characteristics. Figure 1 shows the overall distribution of correctly answered questions with most scores falling between $9-13$. We then identified specific demographic groups with knowledge deficiencies in cardiovascular and cancer risk factors and prevention. As shown in Tables 2, Table 3, ethnicity, annual income, and education level were statistically significant predictors of knowledge deficiencies for both cardiovascular and cancer knowledge. There was a decrease in the percentage of low scores for cancer awareness but not for cardiovascular diseases with increasing age. In all knowledge categories, African American and Hispanic women scored significantly lower than Caucasian women. Figure 2 displays the percentage of participants and number of correctly answered questions in the knowledge categories. Of the four categories, only 
the colon cancer questions received more than $50 \%$ correct responses. Multiple logistic regression analysis demonstrated a significant relationship between education level and the total number of correct answers $(\mathrm{p}=0.01)$.

Table I Demographic characteristics of study participants

\begin{tabular}{|c|c|c|c|}
\hline Total sample $\mathbf{N}=\mathbf{2 5 6}$ & & $\mathbf{N}$ & $\%$ \\
\hline \multirow{4}{*}{ Age } & $18-25$ & 63 & 24.7 \\
\hline & $26-35$ & 111 & 43.5 \\
\hline & $36-45$ & 63 & 24.7 \\
\hline & $46-60$ & 18 & 7.1 \\
\hline \multirow{5}{*}{ Race } & White & 167 & 65.7 \\
\hline & African American & 45 & 17.7 \\
\hline & & & \\
\hline & Hispanic & 24 & 9.4 \\
\hline & Other & 18 & 7.1 \\
\hline \multirow{5}{*}{ Education } & Grade School & 4 & 1.6 \\
\hline & High School & 77 & 30.1 \\
\hline & Bachelor's Degree & 100 & 40 \\
\hline & Master's Degree & 63 & 25.2 \\
\hline & Doctoral Degree & 6 & 2.3 \\
\hline \multirow{5}{*}{ Insurance } & Medicaid & 57 & 23.3 \\
\hline & Medicare & 19 & 7.8 \\
\hline & & & \\
\hline & Private & 158 & 64.5 \\
\hline & Self- Pay & 11 & 4.5 \\
\hline \multirow{2}{*}{ Employed } & Yes & 192 & 75.3 \\
\hline & No & 63 & 24.7 \\
\hline \multirow{3}{*}{ Marital status } & Single & 125 & 49 \\
\hline & Married & 121 & 47.5 \\
\hline & Divorced & 9 & 3.5 \\
\hline \multirow{2}{*}{ Have Children } & Yes & 106 & 41.9 \\
\hline & No & 147 & 58.1 \\
\hline \multirow{3}{*}{ Income } & $<30,000$ & 77 & 30.4 \\
\hline & $30,000-60,000$ & 62 & 24.5 \\
\hline & $>60,000$ & 114 & 45.1 \\
\hline
\end{tabular}

Table 2 Percentage of low vs. high score of cardiovascular disease knowledge

\begin{tabular}{|c|c|c|c|}
\hline & \% Low score & \% High score & P-value \\
\hline \multicolumn{4}{|l|}{ Age } \\
\hline $18-25$ & 28.6 & 71.4 & \multirow{4}{*}{0.6} \\
\hline $26-35$ & 32.4 & 67.6 & \\
\hline $36-45$ & 28.6 & 71.4 & \\
\hline $46-60$ & 44.4 & 55.6 & \\
\hline \multicolumn{4}{|l|}{ Race } \\
\hline Caucasian & 23.4 & 76.6 & \multirow{4}{*}{0.001} \\
\hline African American & 48.9 & 51.1 & \\
\hline Hispanic & 58.3 & 41.7 & \\
\hline Other & 27.8 & 72.2 & \\
\hline \multicolumn{4}{|l|}{ Annual Income } \\
\hline$<30,000$ & 40.3 & 59.7 & \multirow{3}{*}{0.03} \\
\hline $30,000-60,000$ & 33.9 & 66.1 & \\
\hline$>60,000$ & 22.8 & 77.2 & \\
\hline \multicolumn{4}{|l|}{ Education Level } \\
\hline Grade School & 75 & 25 & \multirow{5}{*}{0.04} \\
\hline High School & 36.4 & 63.6 & \\
\hline Bachelor's Degree & 33 & 67 & \\
\hline Masters Degree & 19 & 81 & \\
\hline Doctoral Degree & 16.7 & 83.3 & \\
\hline
\end{tabular}

Table 3 Percentage of low vs. High score of cancer knowledge

\begin{tabular}{|c|c|c|c|}
\hline & \% Low score & \% High score & P-value \\
\hline \multicolumn{4}{|l|}{ Age } \\
\hline $18-25$ & 73 & 27 & \multirow{4}{*}{0.01} \\
\hline $26-35$ & 50.5 & 49.5 & \\
\hline $36-45$ & 47.6 & 52.4 & \\
\hline $46-60$ & 44.4 & 55.6 & \\
\hline \multicolumn{4}{|l|}{ Race } \\
\hline Caucasian & 47.3 & 52.7 & \multirow[t]{4}{*}{0.003} \\
\hline African American & 75.6 & 24.4 & \\
\hline Hispanic & 54.2 & 45.8 & \\
\hline Other & 72.2 & 27.8 & \\
\hline \multicolumn{4}{|l|}{ Annual Income } \\
\hline$<30,000$ & 67.5 & 32.5 & \multirow{3}{*}{0.001} \\
\hline $30,000-60,000$ & 66.1 & 33.9 & \\
\hline$>60,000$ & 40.4 & 59.6 & \\
\hline \multicolumn{4}{|l|}{ Education Level } \\
\hline Grade School & 100 & 0 & \multirow{5}{*}{0.001} \\
\hline High School & 71.4 & 28.6 & \\
\hline $\begin{array}{l}\text { Bachelor's } \\
\text { Degree }\end{array}$ & 44 & 56 & \\
\hline Masters Degree & 47.6 & 52.4 & \\
\hline Doctoral Degree & 33.3 & 66.7 & \\
\hline
\end{tabular}




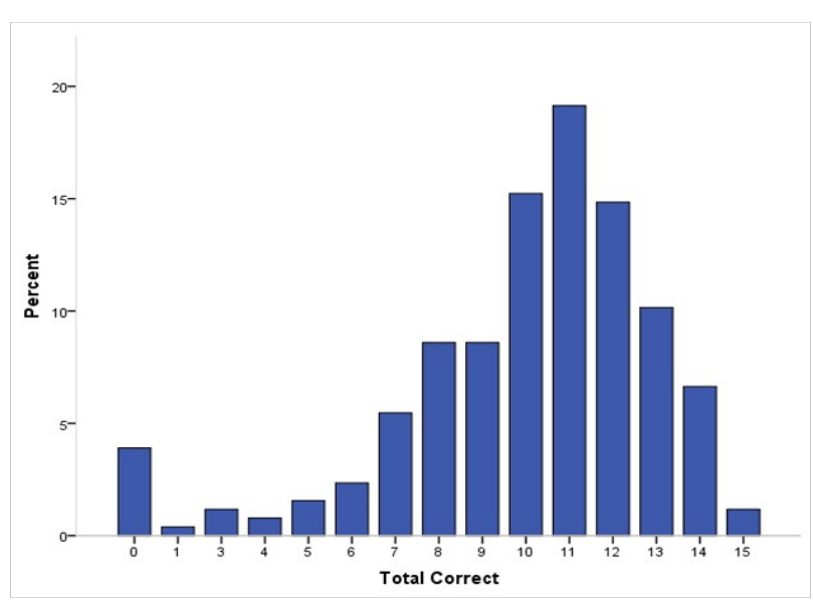

Figure I The distribution of correctly answered questions.

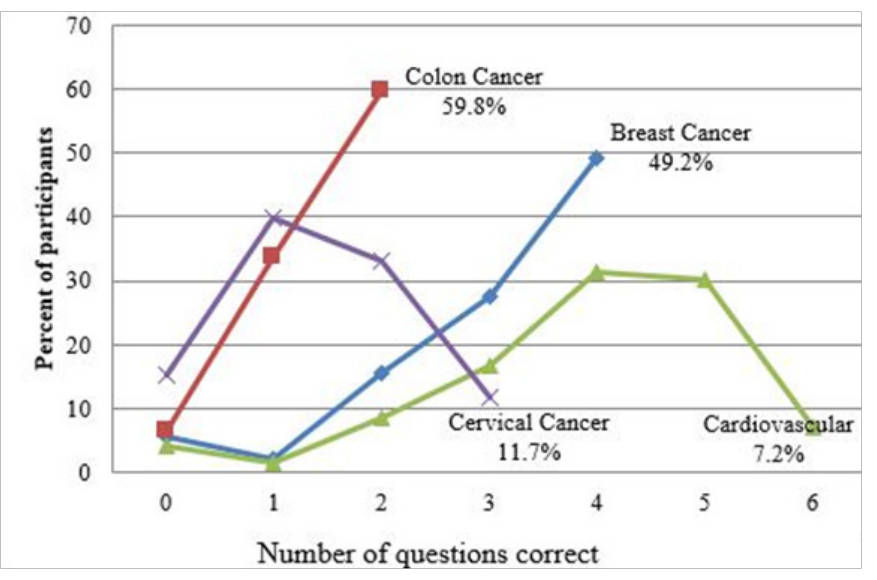

Figure 2 Correctly answered questions by category.

\section{Comment}

We developed and assessed a questionnaire for women seeking obstetric and gynecologic care that focused on major causes of women's morbidity and mortality. Participants represented a broad range of age, ethnic, income, and education groups. We sought to identify knowledge deficiencies about these conditions and the relationships to group demographics. Previous studies have addressed knowledge gaps in women's health care. Fernandez et al reported that only $40 \%$ of women identified smoking and family history as risk factors for CVD; only $5 \%$ of women considered hypertension, $14 \%$ hypercholesterolemia, and $15 \%$ obesity as CVD risk factors. ${ }^{16,17}$ Lack of patient awareness of myocardial infarction symptoms is a common reason for delayed medical care. ${ }^{18}$ Other investigators have identified specific patient groups that need to be targeted for additional counseling for cervical cancer. Fink et al reported that cervical cancer awareness was lowest among ethnic minorities and those with lower levels of education. In the United States the highest incidence of cervical cancer is among Hispanic/Latina women followed by African-American women. ${ }^{19}$ Women with lower income levels were more likely to be positive for high risk HPV. In contrast, those women who received counseling and the HPV vaccine were more likely to adhere to cervical screening recommendations. ${ }^{20-22}$
The strengths of this study are its diverse group of patients with varied demographic characteristics and its focus on four conditions most relevant to women's health. Limitations of this study include the limited number of enrollees and questions included for each disease state. Our findings suggest that current public health programs that have focused on improving patient knowledge and awareness of these health problems have not had their desired impact criterion. While all women should be educated about CVD risk factors, specific focus should be placed on ensuring that women aged 44-60 are educated on prevention strategies. Conversely, more emphasis should be placed on counseling younger women, aged 18-25, on cervical cancer screening and prevention strategies including the HPV vaccine.

The results of our patient survey are particularly relevant to all primary providers of women's health care. In summary, they suggest that education programs on the selected conditions studied should be offered to all female patients with particular emphasis on targeting women from ethnic minority groups with lower income and lower education. While it was beyond the scope of this study to provide the specifics of these programs, the questions selected for the patient survey would appear to offer an entry point for the core content of such educational programs. Women from minority ethnic groups with lower education and income levels would benefit from improved counseling on cardiovascular disease and cancer prevention.

\section{Acknowledgement}

i. Ann Impens, PhD, MPH, Manager of Clinical Research, Research Assistant, Professor, Internal Medicine, Midwestern University, Downers Grove, IL.

ii. Jason M. Kamilar, PhD, Manager of Bio-Clinical Statistics, Midwestern University, Downers Grove, IL

\section{Conflict of interest}

The author declares no conflict of interest.

\section{References}

1. Heron M, Hoyert DL, Murphy SL, et al. Deaths: final data 2006. Natl Vital Stat Rep. 2009;57(14):1-134.

2. Lloyd-Jones D, Adams RJ, Brown TM, et al. Executive summary: heart disease and stroke statistics-2010 update: a report from the American heart association. Circulation. 2010;121(7):948-954.

3. Heart Disease and Stroke. Healthy People 2020; 2012.

4. Ostchega Y, Yoon SS, Hughes J, et al. Hypertension awareness, treatment, and control-continued disparities in adults: United States, 2005-2006. NCHS Data Brief. 2008;(3):1-8.

5. Cancer Facts and Figures. USA: American Cancer Society; 2012.

6. Schueler KM, Chu PW, Smith-Bindman R. Factors associated with mammography utilization: A systematic quantitative review of the literature. J Womens Health (Larchmt). 2008;17(9):1477-1498.

7. ACOG practice bulletin: screening for cervical cancer. Obset Gynecol. 2012;120(5):1222-1238.

8. ACOG Committee opinion: colonoscopy and colorectal cancer screening strategies. Obset Gynecol. 2001;110(5):1199-1202.

9. Vital signs: Colorectal cancer screening among adults aged 50-75 year - United States, 2008. Centers for disease control and prevention (CDC). MMWR Morb Mortal Wkly Rep. 2012;59(26):808-812. 
10. Ferlay J Shin HR, Bray F, et al. Globocan 2008 v1.2, Cancer Incidence and Mortality Worldwide: IARC CancerBase No. 10. Lyon (France) International Agency for Research on Cancer; 2010.

11. Committee opinion: the initial reproductive health visit. Obset Gynecol 2010;460:1-5.

12. Committee opinion: human papillomavirus vaccination. American College of Obstetricians and Gynecologists. 2010;467:1-6.

13. Kahn EB, Ramsey LT, Brownson RC, et al. The effectiveness of interventions to increase physical activity: a systematic review. Am J Prev Med. 2002;22(4S):73-107.

14. Fielding J, Rimer B, Nedrow B, et al. Task force on community preventive services. Recommendations to increase physical activity in communities. Am J Prev Med. 2002;22(4S):67-72.

15. Fielding JE. Increasing physical activity. A report on recommendations of the task force on community preventive services. MMWR. 2001;50(RR18):1-16.

16. Fernandez RS, Salamonson Y, Griffiths R, et al. Awareness of risk factors for coronary heart disease following interventional cardiology: a key concern for nursing practice. Int J Nurs Pract. 2008;14(6):435-442.
17. Flink LE, Sciacca RR, Bier ML, et al. Women at risk for cardiovascular disease lack of knowledge of heart attack symptoms. Clin Cardiol. 2013;36(3):133-138

18. Lefter L. The advanced practice nurse's role regarding women's delay in seeking treatment with myocardial infarction. J Am Acad Nurse Pract. 2000;14(910):449-456

19. Downs LS, Scarinci I, Einstein MH, et al. Overcoming the barriers to the HPV vaccination in high-risk populations in the US. Gynecol Oncol. 2010;117(3):486-490.

20. Kahn JA, LanD, Kahn RS. Sociodemographic factors associated with highrisk human papillomavirus infection. Obstet Gynecol. 2008;110(1):87-95.

21. Anhang Price R, Koshiol J, Kobrin S, et al. Knowledge and intention to participate in cervical cancer screening after the human papilloma vaccine. Vaccine. 2011;29(25):4238-4243.

22. Scarinci IC, Slawson DL, Watson JM, et al. Socioeconomic status, ethnicity, and health care access among young and healthy women. Ethn Dis. 2001;11(1):60-71. 